\title{
Medicine Referred in Poetries in Tang Dynasty-In the Case of Li Bai, Du Fu and Bai Juyi
}

\author{
Chen Liyun, Yan $\mathrm{Na}$ \\ Shanghai University of Traditional Chinese Medicine, Shanghai, China
}

\begin{abstract}
Poetry is an important part of traditional culture, which reached the zenith in Tang dynasty. Li Bai, Du Fu and Bai Juyi are famous poets, and there are much about medicine in their works, such as disease, pathogeny, herbs and life cultivation. Some poets described their feelings about getting sick in their poetries, which showed their psychologic status, social conditions and helped us to learn the development of medicine.
\end{abstract}

Keywords: Tang Dynasty, poetry, medicine

Poetry has been developing in China for thousands of years. During Spring and Autumn and Warring States period of China (770-221 B.C.), The Book of Songs, the first collection of poetry, was finished, and then came the Chu Ci. Poetry reached zenith in Tang dynasty, in both the number of books and the value of art. There were much about medicine in these works, such as the basic theories of TCM (Traditional Chinese Medicine), herbs, clinical medicine, medical stories and life cultivation.

$\mathrm{Du} \mathrm{Fu}$ (712-770), born in a family of officials in Gong Xian, Henan province. His grandfather was Du Shenyan. He named himself "an wild old man in Shaoling" because of his living in Shaoling. Afterwards, he was known as Du Shaoling. He studied very hard, but failed in the national exam. While the An-shi Rebellion arose, he suffered much. He learned medicine because he had little money to turn to a doctor when he was sick, and he picked herbs for sale. So there are much about medicine in his works.

Li Bai (701-762), used to live in Jiangyou, Sichuan province. He was much affected by Taoism. He wrote over 900 poetries, among which there were over 50 pieces about life cultivation.

Bai Juyi (772-846), named himself "hermit of Xiangshan". Yuan Zhen described him: "He knew the rules of rhyming when 5-6 years old, wrote poetries when 15, became a successful candidate in the highest imperial examinations when 27." (Yuan Zhen, A collection of Bai Juyi-Preface). He was an official but quited because of the darkness of government. He accepted the idea of life cultivation of Taoism. There were much about pathogeny, cure methods and basic medical theories in his poetries.

\section{Informations About Pharmacology}

Du Fu built a humble cottage by the Huanhua Creek in Chengdu, and a herb garden beside it, which were much referred in his poetries. He wrote in Gao Nan: "The color of Nan tree is not bright, which appears dark

Chen Liyun, M.D., Professor, Shanghai University of Traditional Chinese Medicine.

Yan Na, Ph.D., Research Assistant, Shanghai University of Traditional Chinese Medicine.

Correspondence concerning this article should be addressed to Rm.8415, No.1200, Cailun Rd. Pudong District, Shanghai, China. 
green by the creek. I built a herb garden and a humble cottage beside it." Du Fu devoted much in the garden. "I was working in the herb garden when messages coming from the government for several times." "I often worry about the corruption of sands which may destroy the fan of garden."

"The stems and fruits are green. Spring came over the humble cottage to the herb garden. Saplings cover the hill, whose roots hide in the gap, and they don't want be seen." (the fourth article from Jueju ) Du Fu had much feelings for herbs, and he expressed it in his poetries. "Hundreds of herbs die in the autumn rain, but Cassia toras stay bright color." (Three poetries For Autumn Rain) "slim leaf with floss, flower-thinning makes it nice. "(Clove). "Fruits in autumn for the poor, flowers in Spring for everyone." (For The Peach Tree).

Du Fu got acquaintance with picking and collection of herbs. "Official Yang: Poria cocos is rare in cold mountains, so it should be picked in warm spring." (Coming Upon Official Yang ).

$\mathrm{Du} \mathrm{Fu}$ had intimate knowledge of processing, e.g. how to wash or solarize. "Wash herbs in Huanhua Creek." (the second article from Jueju)" "Herbs can be solarized without women." (20 Jumbles of Poetries in Qinzhou) "solarize herbs when aging." (Sitting Alone) "to solarize after steaming." (30 Rhymes).

Effects of medicants were much recorded in Du's poetries. "Sealworts make hairs black, good looking will appear years later." (The Mountain of Father in law) "Siberian cocklebur can cure acute laryngeal infection..." (Ask the Houseboy to Pick Siberian Cocklebur). In this poetry, Du Fu recorded the effect of Siberian cocklebur, which is a little poisonous. He also recorded the way to how to process and detoxify Siberian cocklebur. In Urge Zongwen to Build Coops, Du Fu recorded the effect of silkie, which could be used to cure rheumatism and restore qi.

Zheng Qian, a pharmacologist, once identified a medicinal plant From Yuezhi with Du Fu, which was recorded in Du's poetry-10 poetries about accompanying Zheng visiting the General He Mountain. He said that even Shennong did not know this plant.

It was recorded in Allii macrostemi bulbus from Luan Yin Ju in autumn that allii macrostemi bulbus could be used to warm the middle-jiao and cure diseases. So did its shape and color recorded.

\section{The Knowledge About Disease}

There were much about the knowledge of disease in Du Fu's poetries. When he was young, he lived in a rich family. He was in good condition and studied very hard. The poetries finished then were heroic, such as "At the top of Mountain Tai, nothing compares its majesty." (Look up to the Mountain Tai). Later, wars began, and Du Fu lived a poor life and often got sick. His poetries turned sad and there were much about diseases. "Get sick easily for many years, and climb alone." (Climb). "No health but sick for many years. Mr. Wang complained my sick looking." (To Wang Yi). Du Fu had written about 38 poetries about his diseases.

About malaria. "Who can endure getting malaria in late autumn? I suffered cold for hundred days. Hairs white, eyes blurred, got calluses. Skin yellow, wrinkled up, dying." (Met Wang Yi after recovery) Du Fu described the symptoms of malaria, deficiency of vital energy and blood, in this poetry. He thought he got malaria because of drinking the water from Ba River (Sorry for official Zheng and Su from Tai Zhou). In To Mr. Xue, Du Fu recorded his disease from Lung Qi when getting malaria: "Got malaria in the valley, through winter and spring, and got Lung Qi in spring. Such disease must have some reasons."

$\mathrm{Du} \mathrm{Fu}$ often got the disease with the symptom of frequent drinking and urination. His lobi pulmonis turned shrivelled and he was in deep thirsty. "I often got the disease with the symptom of frequent drinking and urination, missing the court day and night. Too much shrivelled, wondering in Gongsun City." (In Chongling 
with Yuan Shi) "Thirsty in the midnight, turned around white haired." (Show Aduan). "Disease of thirsty, where to go? Even more weak in spring." (Over the south mountain To Dongting Lake). "Nothing compares the heat inside of me." (To Official Li). Du Fu thought his disease was "originated from heat" (To Official Liu). If one didn't get recovery soon, there would be complications, such as dim vision, hemiplegia, Sore furuncle, ulcer and deaf.

About pneamopathy. "Got lung disease when returned to the court. It was uncomfortable to catch up." (To Cousin Tang). Du Fu wrote much poetries when he got lung disease, such as The Autumn Valley, The Quiet Autumn, and The North Wind. He suffered such much as to not get up in the late period. "Suffered for so long time because of the lung disease, I could sleep only with the thick pillow. Closed the door early in autumn." (Momentary recovery just before death).

About deaf. Du Fu expressed much depression in Deaf: "Often got dim vision and became deaf last month. Apes shout, I cry in autumn. Sparrows make noise, I feel worried." "Getting old, solarized herbs and called the houseboy by the door. Knowing I am not healthy, why deaf?!" (Sitting alone) "No home, wandering here and there. Hemiplegia in right arm and deaf. Cried in the boat, wrote nothing with brush in the left hand." (2 poetries in Qingming).

$\mathrm{Du} \mathrm{Fu}$ wrote over 100 pieces of poetries about dysphoria and agrypnia, such as hardly fall asleep, no sleep the whole night, fall asleep late and wake up early, dream a lot...

Du Fu wrote much about his bad sleep, when he left friends, such as See Official Yan off, and To Dongdu in late winter. Due to Du's wandering, he seldom lived with family or friends. He often missed them much, so he could not sleep well. "I miss friends in the midnight. Something big stands the way." (Missing friends in Qingxi Hotel). "Lost in the mountain. The sound of chicken remind me of you." (Missing cousin in the boat at snowing night). "Thinking of the splendid tree when leaning on the pillow. Looking at stars against the wall." (To Official Liu).

Wars often caused Du Fu bad sleeps. "Wars continue, how to sleep well?" (For the Thatched Cottage by River). "Soldiers, soldiers, spending years guarding the country...Training and Fighting, wounds over the body. Go home, back earlier..." (The Chant of Summer Night). "Wars and wars, beautiful nights slip away." (Tired Night). "Forts all over the valley, where is the heaven?" (No Sleep). "Can't sleep for the war, I have nothing to make the world right." (Stay Over Night In An Attic By River).

Du Fu recorded tooth disease in his works. "When came to Qin Zhou, my tooth disease recovered." (To Zan Shang Ren). "Me, oh me, only half of teeth and deaf in left ear." (Haze).

Bai Juyi suffered from several diseases, and he wrote his feelings in poetries.

Bai Juyi was in bad condition since his forties. He recorded his senilism in several poetries. "I used to getting senilism. Being the seventh grade official when forty, had to retire because of the disease. Much more people are poorer than me, so I should have nothing to complain. To those who got the same disease as me, don't complain." (To those who got the same disease as me). "Hairs turned white when forty." (Hearting the turtle). "Dim version, white hairs. Senilism, worried. No energy to work. I must retire when 50." (Ask myself).

Bai Juyi described his image in the mirror in Three pieces for getting old. "Look in the mirror in the morning, lonely figure lonely shadow. No more young, but white hairs. Everything is fading. The image is older than it in yesterday."

"Holding a bunch of hairs, high density and straight. Black then, white now. Sigh before looking in the mirror. I don't want scrub the mirror for white hairs. Duck's head and crane's neck, black all the time. But the 
human's hair must turn white someday."

"Buried peach seeds the year before last, now they grow trees of flowers. Babies born last year, now they are learning how to walk. Everything's growing up, oh, I'm old! Youth went away, nothing could call it back. Writing down what I feel today, to my folks. Enjoy, just enjoy yourself when young, or you'll regret when old."

Bai Juyi suffered much from eye disease. "I can't see clearly, and it seems night to me. White sideburns, sad just like in autumn." (Answer the augur). "Dim version, white sideburns. Lonely under stars. Severe eye disease, rest should be taken." (Separation). "Read too much when young, tears much when old. I hurt eyes myself, how I regret! When night falling, it seems barely light to me. I can't see clearly in the early morning, which makes me think that the mirror is not clean. Nothing could cure this disease, I should close my eyes and learn from Dhūta." (Dim version). "Head-wind, blur sihgt, getting old. Worse and worse, no cure. I could see only big font clearly, small ones make me worried. I can't tell black or white. But I should have no regret, then I needn't be worried." (Blur sight).

Because of the eye disease, Bai Juyi often got sleepless. "I can't fall asleep not for the Chinese New Year's Eve, but the eye disease. I think about many things before the new year's coming." (Chinese New Year's Eve). "Getting older, eyes worse. Like warm, looking forward to spring." (15 pieces finished when sick: sigh for disease at the end of the year).

"One is old, deficiency of blood, decay of teeth, worse and worse gums. Fear and panic, how to live a peaceful life? I was 66 years old at the second year of Kaicheng. Thin image, dark shin, white hairs, feeble. Really old! Two teeth fell, how old!" (Teeth's Fall). When Bai Juyi was 68, he wrote: "Head-wind should be cured when reading poetries. Keep smile even teeth broken." (15 pieces finished when sick: verse while drinking with old friends). "Hairs getting short, teeth getting less." (The 12th of 23 pieces in Hewei: in Chinese New Year's Eve).

\section{Pathogeny and Cure}

Du Fu knew medicine. He cured himself and others. "The old lady got pain or numbness, and the young girl asked about Head-wind." (To Mr. Yan). "Black face skin, how to be generous?" (For Su Sixi) "Radix bupleuri is needed for the disease. The decoction may activate sweating often. I miss you and want to pay the debt of gratitude. It is hard to find medicants in the valley..." (To Official Wei Youxia).

Bai Juyi recorded many cures of diseases, including internal medicine, surgery orthopedics and traumatology, eye disease and oral disease. In Dim Version: "Got dim version when spring coming, and I didn’t have mood for anything. I used the fluid of coptis as many as I could, but not very effective." It showed that weather (spring) might be the cause of Bai's eye disease and it was difficult to cure. Bai almost closed eyes all day long so as not to harm them. "Thousands of snowflakes falling down, everything got a gauze covered likely. Even in a clear day, I see things like in fog. Even not in spring, I can see many flowers (because Bai could not see clearly, he would see somethings like flowers). The monk said I saw something because I was thinking of something. The doctor said its resource was the liver. I was cured in both ways. Neither the medicants nor Buddha could cure it." "Suffered from eye diseases for many years. It was very hard to cure because the cause of disease was ingrain. The doctor asked me to stop drinking at first, and the Taoist asked me to resign from the government as soon as possible." "Theories of Nāgārjunabodhisattva all over the desk, pills of Cassia tora just in the box. Suddenly I understand, no cure in the world!" (2 poetries for eye disease). 
In For Taoist Zhang, Bai Juyi thought that the cause of lung disease was over drinking.

Bai Juyi recorded psychotherapy in his poetry, "Don't worry about aging and diseases, and the hear can cure itself." (Occasional versing in the abbey). So did Li Bai. "Worries may hurt people and make hairs black to white." (Sorrow Song).

Bai Juyi told the inner and outer causes of diseases in Qi of Disease: "I know that my unsteady Qi is caused by my emotions. How can I control my emotions to balance the Qi? How old is the disease? I was born with it." Angry is one of the seven emotions. The disease caused by inner factors is called emotional disease.

Bai Juyi talked about cold-evil attacking lung in Writing When Sick: "Cough because of cold, anemogenous phlegm for the coming rain."

Bai Juyi wrote down his feelings when got wandering arthritis in 15 Poetries When Sick: "I got wandering arthritis in the day of Jiayin in winter. Dizzy and disabled left foot. Maybe all diseases related to old age come together." "I am a weak man of 60. Hundreds of diseases ambushed and attacked me. Rotten trees can't avoid bristletails and winds come easily through an empty cave."

\section{Life Cultivation}

The word "Yang Sheng" (life cultivation) was first recorded in Lv Shi Chun Qiu: "Those who know how to live won't do anything bad to living, which is called Yang Sheng." Lao Zi was the representative of Taoism in the late of Chunqiu period. His main ideas about Yang Sheng: "empty the mind, and keep quiet and calm", "everything holds its position because of peace and quiet", "don't think or desire too much", "the best kindness is like water", "if anything or anyone gets too strong, it will turn old. Because it doesn't follow the natural rule. This should be stopped as early as one can." (Tao Te King). The core idea of Lao Zi is "stay quiet and do nothing". Zhuang Zi developed the idea of Lao Zi. He insisted that Yang Sheng should follow the nature: "Stay quiet and clear mind, don't do much, nor think too much. If so, one can live a long life." Taoists adore "behave naturally", "do nothing", "return to the very beginning" and "do mercy and frugality, don't be the first one to do anything."

Li Bai was quite affected by Taoism. He valued the original Qi and life cultivation according to weather and times. "Never be arrogant or irritable, and stayed low even when smooth going." (The Roc) "Yinyang is the kitchen, and the nature is the tool. Eat Promordial Qi and drink the Qi of Yinyang." (The Great Building)" "If according to goodness, everything will enjoy the excellent spirit and soul just like after sexual intercourse." (A Gift for Liu Guandi). Promordial Qi controls "live or die": "Sun rises from east, which looks like from the bottom of the earth. Reach the sky and jump into the sea. Is the house of the six dragons in good condition? Never-ending. If without Promordial Qi, how can people stay long with it?"

Li Bai adored the spirit of Taoism very much: "He love quiet and true life....would love to live in Minggao Mountain and separate the material world." (See the Cousin of Father-in-law off). He recorded some ways of how to breath: "According to the very beginning of Taoism, in order to live a long life. If hungry, have Promordial Qi." (The Roc). "I just know that one took gold liquid when exercise his Qi." (A Melody Played by Sheng). "Push aside the branches and pick the red fruits, take pills to make bones strong as gold." (Watching the Dawn on the Roof). Li Bai referred several times about alchemy: "I worried that the alchemy fluid was finished too late, so that I couldn't realize my dreams." (The 4th Poem of Ancientry). Li Bai wanted to be supernatural being through alchemy, so alchemies referred in his poetries were quite limited. Li Bai insisted on bland diet: "Why not having bland diet?" (Hunting). 
Bai Juyi was deeply affected by Taoism and he was not in good health, so he had deep feelings about life cultivation. Clicking teeth is a good way to prevent some diseases. Bai was used to clicking teeth in the morning. Zhang Nanben drew a picture of Bai's clicking teeth, and it was recorded in Shu Zhong Guang Ji in the years of Zhonghe, which meant clicking teeth was very popular then.

Every organic life follows the rule: born, grow, mature, age, and die. "What doesn't mature or age?" (Explain the Truth). "It is said that those who are good at medicine are called Bian Que, and they can cure any disease but aging." (Sigh for Aging). One can prolong the process of aging by recuperating. Bai Juyi said: "If one, who often got sick when young, works too much while he doesn't recuperate, how can he afford aging?" (Bing Zhong Zuo).

Bai Juyi insisted on less desire: "Nothing in the heart, just like a boat floating freely." (Cold Autumn). "You know the nature so well, and get broad-minded." (Verse for Mr. Zheng Living in Seclusion). "Away from profit and prostitution. Keep oneself quiet and balance." (Stay in the Jianji Temple).

The balance of spirit and emotion plays an important role in preventing diseases. Bai Juyi's Be Happy and Generous talked much about it.

Alchemy was valued by Taoists. Bai Juyi thought, one should take alchemy and do exercise. "Used to make alchemy and took much care on the fire. Some cinnabar is left over in the stove and it is useless for it's dried". (The Only Choice). Sitting in meditation and taking Qi were also recorded. Bai Juyi described the way and feeling of exercising Qi: "Close eyes, sitting in the sun. Balancing Qi will do good to skin and flesh. Like drinking good wine at first, then like awake from hibernating. Feeling comfortable all over the body, nothing in the mind. Forget where I am, stay in peace." (For Winter).

"Build house with cogongrass, plant taros, and farm with fire." (Stay in Jiangpu For The Night). "The water of Yu Spring is very clean. I fly into the clouds. Beautiful water, clean mind. Green stick, white scarf. Climb down the mountain, they know who I am." (For Yu Spring Temple). Bai Juyi said that farming may keep the body strong and living in the nature can keep both body and mind good.

Bland diet. "Keep bland diet in midsummer, no meat. I feel comfortable all over and like flying...I am over 50 years old. My Qi and spirit is weak. Sideburns white, it is difficult to strengthen the pubic region. Less meat diet, more comfortable. Take off the scarf to recuperate and live to the natural death." (Fast in Mid-summer).

To keep good sleep: "sleeping early can avoid hundreds of diseases." (Avoiding summer heat in Qiye House, Tianzhu Temple).

Poetry is an important part of traditional culture, and there were much about medicine in it, such as disease, pathogeny, herbs and life cultivation. Some poetries described their feelings about getting sick in their poetries, which showed their psychologic status, social conditions and helped us to learn the development of medicine.

\section{References}

Xie, S. W. (Ed.). (2005). The poetries of Du Fu. Beijing: People's Literature Publishing House.

Fu, D. H. (Ed.). (1934). The poetries of Du Fu. Shanghai: The Commercial Press.

Peng, D. Q. (Ed.). (2004). A complete collection of Tang-poetry (Vol. 8). Yanji: Yanbian People's Press.

Zhang, C. S. (Ed.). (1983). A complete collection of Tang-poetry. (Vol. 5). Beijing: Zhonghua Book Company. 